\title{
Tarefas propostas por futuros professores dos primeiros anos para ensinar probabilidades
}

\author{
José António Fernandes' \\ María Magdalena Gea" \\ Leandro do Nascimento Diniz"l

\section{RESUMO}

Recentemente, tem-se visto o aprofundamento do ensino de probabilidades e estatística no ensino básico, e importa investigar se o conhecimento dos futuros professores é adequado para ensinar esses temas. Participaram do estudo 53 estudantes do $2 .^{\circ}$ ano do curso de Licenciatura em Educação Básica de uma universidade de Portugal, tendo-lhes sido pedido para resolverem várias questões de probabilidades, sendo aqui estudada apenas aquela que se refere à dimensão didática do conhecimento do futuro professor, quando estabelecem tarefas de probabilidades adequadas para alunos dos primeiros anos. Em termos de resultados obtidos, verificou-se que a maioria dos futuros professores apresentou tarefas nada adequadas ao nível cognitivo dos alunos a quem se destinavam, sendo, em geral, demasiado difíceis e sem fazerem referência à incerteza. As tarefas são muito semelhantes às aprendizagens que os próprios futuros professores realizaram no âmbito do tema de probabilidades.

\section{PALAVRAS-CHAVE}

conhecimento para ensinar; tarefas; probabilidades; futuros professores; primeiros anos escolares.

'Universidade do Minho, Minho, Portugal.

"Universidade de Granada, Granada, Espanha.

"'Universidade Federal do Recôncavo da Bahia, Amargosa, BA, Brasil. 


\title{
TASKS PROPOSED BY PROSPECTIVE TEACHERS OF THE FIRST SCHOOL YEARS TO TEACH PROBABILITY
}

\begin{abstract}
Recently we have witnessed the deepening of the teaching of Probability and Statistics in basic education, where it is important to investigate if the knowledge of prospective teachers is adequate to teach these subjects. 53 students, who were attending the 2nd year of the Bachelor's Degree in Basic Education at a university in Portugal, were asked to solve various questions on probability. We study only the one that refers to the didactic dimension of the prospective teacher's knowledge, when they establish tasks of probability suitable for students of the primary education. In the results obtained, it was found that the majority of participants presented inappropriate tasks to the cognitive level of the students for whom they were intended, and they were generally too difficult and without reference to uncertainty. The tasks were very similar to the learning that the prospective teachers themselves have done under the topic of probability in their previous training.
\end{abstract}

KEYWORDS

knowledge to teaching; tasks; probability; prospective teachers; primary education.

\section{TAREAS PROPUESTAS POR FUTUROS PROFESORES DE PRIMEROS AÑOS ESCOLARES PARA ENSEÑAR PROBABILIDADES}

\section{RESUMEN}

En la actualidad asistimos a una profundización de la Estadística y la Probabilidad en la enseñanza básica, donde interesa investigar si el conocimiento de los futuros profesores es adecuado para enseñar estos temas. Participaron en el estudio 53 estudiantes de $2 .^{\circ}$ año de la Licenciatura en Educación Básica de una universidad de Portugal, a los que se pidió que resolvieran varias cuestiones sobre probabilidad. En este trabajo analizamos solo la cuestión que se refiere a la dimensión didáctica del conocimiento del futuro profesor, cuando establecen tareas de probabilidad adecuadas a alumnos de los primeros años de enseñanza básica. En cuanto a los resultados obtenidos, la mayoría de futuros profesores presentaron tareas nada adecuadas al nivel cognitivo de los alumnos a los que estaban destinados, siendo, en general, demasiado difíciles y sin referencia a la incertidumbre. Las tareas son muy semejantes a los aprendizajes que los propios futuros profesores recibieron en el tema de probabilidad.

PALABRAS CLAVE

conocimiento para la enseñanza; tareas; probabilidad; futuros profesores; enseñanza básica. 


\section{INTRODUÇÃO}

O desenvolvimento científico da estatística e das probabilidades, que se verificou no século passado, tem-se repercutido numa maior visibilidade por meio das suas aplicações sociais, profissionais e pessoais. Tal aprofundamento do uso da estatística e das probabilidades tem-se também refletido na escola, ao se incluir tais temas nos programas escolares atuais de Matemática de todos os anos dos ensinos básico e secundário ${ }^{1}$.

No ensino básico, sobretudo no tema de probabilidades, viram-se algumas mudanças no programa atual (Portugal, 2013) em relação ao programa anterior (Portugal, 2007). Entre os variados aspectos que foram modificados (ver Alves e Fernandes, 2015), do nosso ponto de vista, a alteração mais significativa diz respeito à inclusão do tema de probabilidades apenas no $90^{\circ}$ ano de escolaridade, que é o último ano escolar do ensino básico em Portugal. Ora, tal alteração é problemática, pois, segundo a investigação, retardar o ensino das probabilidades permite que as muitas ideias erradas dos alunos nesse tema se consolidem (Batanero, 2013; Borovcnik e Peard, 1996; Fischbein e Schnarch, 1997). Esse aspecto é destacado nas orientações curriculares de outros países, como é o caso do National Council of Teachers of Mathematics (2007, p. 52), que afirma: "A crescente ênfase curricular atribuída à análise de dados proposta por estas Normas pretende abranger todos os anos de escolaridade, em vez de estar apenas limitada ao $3^{\circ}$ ciclo e ao secundário, como é comum em muitos países".

Independentemente do programa nos dias atuais em vigor, consideramos ser importante e necessário que os futuros professores dos primeiros anos escolares adquiram conhecimentos básicos de probabilidades, seja porque esse tema lida com a incerteza, por contraponto ao determinismo, seja porque se espera que futuramente ele seja ensinado antes do $9 .^{\circ}$ ano, e, ainda, porque esse conhecimento faz parte, cada vez mais, da vida cotidiana das pessoas (Batanero e Chernoff, 2018).

Por outro lado, o atual alargamento, ou pelo menos num futuro próximo, do estudo desse assunto a todos os alunos durante toda a escolaridade recomenda a realização de investigação no âmbito do ensino e, portanto, sobre professores ou professores em formação (Batanero, 2009; Batanero et al., 2016).

Nesse contexto, no presente estudo, investiga-se o conhecimento para ensinar probabilidades de futuros professores dos primeiros anos escolares, ou seja, do $10^{\circ}$ e do $2 .^{\circ}$ ciclo do ensino básico. O conhecimento para ensinar é multifacetado e tem sido objeto de amplas pesquisas nos últimos anos (veem-se, por exemplo, Hill et al., 2007; Llinares e Krainer, 2006; Ponte, 2012). Em todos esses trabalhos, identificam-se dois tipos de conhecimento fundamentais para o ensino: o conhecimento do conteúdo e o conhecimento didático (ou especializado) desse conteúdo (e.g., Godino, 2009; Hill, Ball e Schilling, 2008; Shulman, 1986).

1 Em Portugal, o ensino básico desenvolve-se ao longo dos primeiros nove anos de escolaridade e estrutura-se em três ciclos: $1 .^{\circ}$ ciclo, do $1 .^{\circ}$ ano ao $4 .^{\circ}$ ano; $2 .^{\circ}$ ciclo, $5 .^{\circ}$ e $6 .^{\circ}$ anos; e $3 .^{\circ}$ ciclo, do $7 .^{\circ}$ ano ao $9 .^{\circ}$ ano. Já o ensino secundário se desenvolve ao longo dos últimos três anos de escolaridade, do $10 .^{\circ}$ ano ao $12 .^{\circ}$ ano. 
Neste trabalho, baseamo-nos no modelo de conhecimento didático-matemático (CDM) do professor descrito no marco teórico do enfoque ontossemiótico (Godino, 2009; Godino et al., 2017; Pino-Fan e Godino, 2015), centrando a atenção nas componentes epistêmica, cognitiva e ecológica da sua dimensão didática, que se relacionam com as diferentes facetas da idoneidade didática que os autores introduzem para desenhar ou avaliar o ensino e a aprendizagem da matemática. Para tal, aqui, analisamos as tarefas de probabilidades estabelecidas por uma amostra de 53 futuros professores adequadas para alunos do $1 .^{\circ}$ e do $2 .^{\circ}$ ciclo do ensino básico. Embora a definição de tarefas de ensino seja uma exigência da ação cotidiana do professor, constata-se que se trata de uma problemática pouco estudada em termos de investigação educacional em probabilidades.

Nas seções seguintes, apresentam-se o enquadramento teórico do estudo, o método utilizado, os resultados obtidos segundo a caracterização das tarefas propostas pelos futuros professores e, finalmente, as conclusões do estudo, com algumas considerações finais sobre as suas implicações para o ensino do tema no ensino básico.

\section{ENQUADRAMENTO TEÓRICO}

\section{O CONHECIMENTO PARA ENSINAR}

Shulman (1986) foi pioneiro no estudo da questão do conhecimento do professor para ensinar, identificando três grandes componentes de conhecimento que intervêm no ato de ensinar, designadamente:

- o conhecimento do conteúdo, que diz respeito aquilo que se vai ensinar, tanto na sua vertente sintática como semântica;

- o conhecimento pedagógico do conteúdo, que é relativo às formas como o professor representa e formula o conhecimento do conteúdo quando ensina, para torná-lo compreensível para o aluno;

- o conhecimento do currículo, que se refere ao conhecimento acerca dos programas escolares, das indicações pedagógicas neles existentes e dos materiais de ensino.

Para o presente estudo, revestem-se de uma importância especial todas essas componentes do conhecimento para ensinar.

Com base no trabalho de Shulman (1986), Hill, Ball e Schilling (2008) distinguem duas grandes categorias de conhecimento relevantes para ensinar: $\mathrm{o}$ conhecimento matemático e o conhecimento pedagógico do conteúdo. A primeira categoria desdobra-se em três subcategorias: o conhecimento comum do conteúdo, que se refere ao conhecimento que uma pessoa (não necessariamente professor) mobiliza para resolver problemas matemáticos; o conhecimento especializado do conteúdo, que diz respeito ao conhecimento especial do professor e que o habilita a planificar e desenvolver sequências de ensino; e o conhecimento no horizonte matemático, que abrange conteúdos mais avançados do que os que se ensinam, incluindo também aspectos históricos e filosóficos que proporcionam perspectivas ao professor. A segunda ca- 
tegoria inclui também três subcategorias: o conhecimento do conteúdo e os estudantes, concernente ao conhecimento sobre como os estudantes pensam, conceitualizam ou aprendem um conteúdo; o conhecimento do conteúdo e o ensino, que é o conhecimento que resulta da integração do conhecimento do conteúdo matemático com o conhecimento sobre o ensino desse conteúdo; e o conbecimento do currículo, pertinente ao conhecimento, orientações, fins e motivações das diretrizes curriculares, materiais curriculares e sequencialização do tema nos diferentes níveis escolares.

Ampliando e detalhando os modelos anteriores, Godino e colaboradores (Godino, 2009; Godino, Batanero e Font, 2007; Godino et al., 2017; Pino-Fan e Godino, 2015) estabelecem três dimensões que caracterizam os conhecimentos do professor: dimensão matemática, relativa ao conhecimento matemático não necessariamente orientado para o ensino, apontado tanto a um nível educativo concreto como na sua relação com níveis posteriores; dimensão didática, que se refere ao conhecimento dos fatores que influem na planificação e implementação do processo de ensino do tema; e dimensão metadidático-matemática, que diz respeito ao conhecimento da própria prática docente, assim como das normas, metanormas e restrições contextuais que a influenciam, com o objetivo de detectar possíveis melhorias.

No nosso estudo, centramo-nos na dimensão didática do CDM, que se subdivide nas seguintes componentes (Pino-Fan e Godino, 2015):

- a faceta epistêmica: o conhecimento especializado da dimensão matemática na vertente institucional em que se realiza o processo de aprendizagem (situações-problema, linguagens, procedimentos, definições, propriedades e argumentos);

- a faceta cognitiva: o conhecimento de aspectos cognitivos dos estudantes, atendendo aos seus conhecimentos pessoais e à progressão das suas aprendizagens;

- a faceta afetiva: o conhecimento dos estados afetivos (atitudes, emoções, crenças, valores) de cada aluno em relação aos objetos matemáticos e ao processo de estudo seguido;

- a faceta mediacional: o conhecimento dos recursos de ensino e à atribuição do tempo às distintas ações e processos;

- a faceta interacional: o conhecimento sobre os padrões de interação na aula e sua sequencialização orientada para a fixação e negociação de significados;

- a faceta ecológica, que enfatiza o sistema de relações com o contexto social, político e econômico.

Para analisar o conhecimento sobre probabilidades dos futuros professores no nosso estudo, analisamos as tarefas que eles propõem e a sua adequação a alunos do $1 .^{\circ}$ e do $2 .^{\circ}$ ciclo do ensino básico. Prestamos atenção ao conteúdo matemático que fundamenta a tarefa proposta (faceta epistêmica), se o nível educativo é adequado e se os alunos dispõem de conhecimentos prévios suficientes para enfrentar com êxito a tarefa (faceta cognitiva), assim como o contexto em que esta surge e se atende às diretrizes curriculares (faceta ecológica). 


\section{O CONHECIMENTO PARA ENSINAR PROBABILIDADES NOS PRIMEIROS ANOS}

No programa escolar de Matemática do ensino básico em Portugal (Portugal, 2007), identificam-se os conteúdos do tema de probabilidades que são incluídos nos diferentes ciclos do ensino básico. No 1. ${ }^{\circ}$ ciclo, inclui-se o tópico "Situações aleatórias", especificando-se que se trata de "explorar situações aleatórias que envolvam o conceito de acaso e utilizar o vocabulário próprio para as descrever (certo, possível, impossível, provável e improvável)"(Portugal,2007,p.28). A título de exemplo, refere-se às situações de extração de um berlinde de um saco com berlindes de várias cores, o lançamento de um dado com faces numeradas de 1 a 6 e o registro do número de carros vermelhos que passam à frente da escola no intervalo da manhã. Espera-se ainda que nessas situações os alunos ordenem acontecimentos numa escala do menos provável ao mais provável.

No 2. ${ }^{\circ}$ ciclo, em continuação do que foi estudado no $1 .^{\circ}$ ciclo, os alunos devem realizar experiências aleatórias para explorar a regularidade a longo termo, tendo em vista identificar e listar todos os resultados possíveis associados às respectivas experiências aleatórias, como, por exemplo, lançar dois dados e registrar o resultado da soma das pintas das faces que ficam voltadas para cima ou extrair duas bolas de uma caixa, sem reposição ou com reposição.

Finalmente, enquanto nos ciclos anteriores os alunos trabalham informalmente a noção do acaso e utilizam vocabulário básico relativo às situações aleatórias, no $3 .^{\circ}$ ciclo, aprofunda-se o estudo do tema considerando a probabilidade como um valor numérico do intervalo $[0,1]$, os conceitos clássico e frequencista de probabilidade e os acontecimentos disjuntos e complementares.

Os estudos sobre o conhecimento dos professores e futuros professores dos primeiros anos para ensinar probabilidades têm-se focado, sobretudo, no conhecimento de probabilidades, o qual se tem revelado muito limitado. Por exemplo, num estudo com 69 futuros professores do ensino primário envolvendo o cálculo da probabilidade simples, composta e condicionada com base em dados apresentados numa tabela de dupla entrada, Contreras et al. (2010) concluíram que os futuros professores tiveram grande dificuldade no cálculo da probabilidade condicionada e conjunta e alguns deles aderiram a raciocínios falaciosos, como a falácia da condicional transposta (trocar o acontecimento condicionante com o condicionado) e a falácia da conjunção (atribuir à probabilidade da interseção de dois acontecimentos valor superior à probabilidade de um desses acontecimentos).

Também num estudo com futuros professores dos primeiros anos de escolaridade, Fernandes, Viseu e Gea (2016) constataram que os futuros professores, excetuando o caso da probabilidade simples, em que foram mais bem-sucedidos, demonstraram desempenho limitado nos itens sobre a definição de acontecimentos certos e sobre a probabilidade condicionada e desempenho muito limitado na probabilidade conjunta. Segundo esses autores, quando se trabalha no contexto da extração com ou sem reposição, a maior dificuldade dos alunos na probabilidade conjunta pode dever-se ao fato de esse conceito ser mais elaborado do que o conceito de probabilidade condicionada numa vertente de restrição do espaço amostral.

Noutra pesquisa, Fernandes et al. (2014) observaram que as dificuldades dos futuros professores dos primeiros anos em probabilidade conjunta e condicionada 
resultaram de combinar erradamente os valores da probabilidade conjunta, em que se destaca a aplicação da operação de adição em vez da de multiplicação, de considerar apenas a probabilidade de uma das duas ordens possíveis, de determinar o valor de probabilidade de um dos acontecimentos implicados, de ignorar o acontecimento condicionante, de confundir probabilidade condicionada com probabilidade conjunta, de levar em conta indevidamente a reposição ou a não reposição e de referir casos favoráveis e casos possíveis sem os combinar.

Finalmente, Alsina e Vásquez (2016) conduziram um estudo sobre o CDM em probabilidades de 93 professores chilenos do ensino primário em exercício, tendo-se evidenciado vários erros e dificuldades, bem como a adesão a heurísticas e enviesamentos probabilísticos. Diante desses resultados, os autores defendem que é necessário que os professores aprofundem o seu CDM do conteúdo.

\section{MÉTODO}

O estudo aqui apresentado teve por objetivo averiguar o conhecimento de futuros professores dos primeiros anos para ensinar probabilidades, destacando-se nesse conhecimento as facetas epistêmica, cognitiva e ecológica (Godino, 2009; Godino et al., 2017; Pino-Fan e Godino, 2015).

Participaram do estudo 53 estudantes (designados por $E_{i}$, com $i=1,2,3, \ldots$, 53) que se encontravam a frequentar o 2. ${ }^{\circ}$ ano do curso de Licenciatura em Educação Básica de uma universidade do norte de Portugal. À entrada na universidade, esses estudantes tinham uma formação muito variada em Matemática, o que explica o fato de muitos deles terem declarado ter dificuldades nessa disciplina. Especificamente, $51,0 \%$ declararam ter dificuldades ou muitas dificuldades, $41,5 \%$ disseram ter poucas dificuldades, e apenas 7,5\% afirmaram não ter dificuldades.

No âmbito do estudo, os participantes resolveram várias questões sobre probabilidades, que foram administradas num contexto de avaliação formal em sala de aula, das quais é aqui estudada apenas uma (Figura 1). Desse modo, os dados usados na investigação foram obtidos numa situação escolar normal, em sala de aula, o que é visto pelos estudantes como uma tarefa habitual da escola e cuja qualificação seria parte da avaliação da disciplina de Probabilidades e Estatística. Mesmo assim, os investigadores informaram os participantes sobre o seu papel na investigação e que as suas respostas, quando usadas como parte da pesquisa, seriam sempre apresentadas de modo a preservar-se o anonimato, criando-se, para tal, códigos para nomear os estudantes, como foi antes dito.

\begin{tabular}{|c|c|}
\hline \multicolumn{2}{|c|}{$\begin{array}{l}\text { Defina três tarefas que sejam adequadas para alunos do } 1 .^{\circ} \text { ou do } 2 .^{\circ} \text { ciclo } \\
\text { do ensino básico aprenderem probabilidades. }\end{array}$} \\
\hline Tarefa 1 & \begin{tabular}{|l}
$\square$ c $1 .^{\circ}$ ciclo \\
$\square$ c $2 .^{\circ}$ ciclo \\
\end{tabular} \\
\hline Tarefa 2 & $\begin{array}{l}\square \text { c 1. }{ }^{\circ} \text { ciclo } \\
\square \text { c } 2 .^{\circ} \text { ciclo }\end{array}$ \\
\hline Tarefa 3 & $\begin{array}{l}\square \text { c } 1 .^{\circ} \text { ciclo } \\
\square \text { c } 2 .^{\circ} \text { ciclo }\end{array}$ \\
\hline
\end{tabular}

Figura 1 - Enunciado da tarefa proposta aos futuros professores. 
$\mathrm{Na}$ questão foi solicitado aos futuros professores que estabelecessem três tarefas de probabilidades adequadas para alunos do $1 .^{\circ}$ ou do $2 .^{\circ}$ ciclo do ensino básico. $\mathrm{Na}$ altura em que os futuros professores resolveram a questão proposta, eles já tinham estudado o tema de probabilidades no âmbito de uma unidade curricular do curso de Licenciatura em Educação Básica, que foi abordado numa perspetiva de conteúdo matemático.

Finalmente, em termos de análise de dados, estudamos as tarefas propostas pelos futuros professores numa perspetiva de análise de conteúdo, que é um tipo de análise qualitativa em que se identificam unidades de texto que se classificam num número reduzido de categorias (Weber, 1985), adotando as seguintes variáveis predefinidas para analisar o conhecimento dos futuros professores nas facetas epistêmica, cognitiva e ecológica: tipo de experiência aleatória, tipo de atividade requerida, contexto e referência à incerteza. Para cada uma dessas variáveis, estabeleceram-se categorias com base na análise das tarefas apresentadas pelos participantes, que são descritas na próxima seção, e em relação às quais são apontados percentagens de futuros professores nelas incluídos e exemplos de tarefas por eles propostas.

\section{CARACTERIZAÇÃO DAS TAREFAS PROPOSTAS PELOS FUTUROS PROFESSORES}

Nesta seção, de resultados e discussão, analisam-se as tarefas de probabilidades propostas pelos futuros professores segundo as variáveis predefinidas antes mencionadas e as categorias aqui definidas.

\section{Tipo de experiência aleatória}

Das tarefas propostas pelos alunos, distinguem-se as relativas a experiências aleatórias simples das que se referem a experiências aleatórias compostas. Uma experiência aleatória simples refere-se a uma única experiência aleatória, como lançar uma moeda ao ar uma vez ou extrair, sem ver, uma bola de um saco, enquanto uma experiência aleatória composta envolve mais do que uma experiência aleatória simples, como, por exemplo, lançar duas vezes a mesma moeda ao ar ou extrair, sem ver, duas bolas de um saco.

Ora, a definição de acontecimentos e a determinação de probabilidades são muito mais complexas no caso das experiências compostas do que no caso das experiências simples, como se demonstra na literatura (e.g., Fernandes, 2001; Polaki, 2005; Watson, 2005). Essas dificuldades derivam, por exemplo, da maior complexidade em determinar o número de casos favoráveis e possíveis, que requerem técnicas de contagem mais elaboradas. $\mathrm{Na}$ Tabela 1 , encontram-se registrados as frequências e as percentagens das tarefas relativas a cada tipo de experiência aleatória, segundo o ciclo de ensino.

Tabela 1 - Frequência (\%) de tarefas segundo o tipo de experiência aleatória e o ciclo de ensino.

\begin{tabular}{l|c|c|c}
\hline \multirow{2}{*}{$\begin{array}{l}\text { Tipo de experiência } \\
\text { aleatória }\end{array}$} & \multicolumn{2}{|c|}{ Ciclo de ensino } & \multirow{2}{*}{ Total } \\
\cline { 2 - 3 } & 1. $^{\mathbf{0}}$ ciclo & 2. $^{\text { ciclo }}$ & \\
\hline Simples & $70(85)$ & $53(69)$ & $123(77)$ \\
\hline Composta & $8(10)$ & $20(26)$ & $28(18)$ \\
\hline Indefinida & $4(5)$ & $4(5)$ & $8(5)$ \\
\hline
\end{tabular}


Observando a informação da Tabela 1, verifica-se que prevalecem as tarefas envolvendo a determinação de probabilidades em experiências simples em relação às experiências compostas ( $77 \%$ contra $18 \%)$, tendência que se mantém em qualquer dos ciclos, com maior incidência no $1 .^{\circ}$ ciclo do que no $2 .^{\circ}$. Em consequência, a menor incidência no $2 .^{\circ}$ ciclo de tarefas envolvendo a determinação de probabilidades em experiências simples é compensada pela maior incidência (mais do dobro), relativamente ao $1 .^{\circ}$ ciclo, de tarefas envolvendo a determinação de probabilidades em experiências compostas.

As tarefas envolvendo a determinação de probabilidades em experiências compostas, as quais resultam da repetição de uma mesma experiência aleatória simples ou de experiências aleatórias simples distintas, assumem-se como tarefas demasiado difíceis para os alunos quer do $1 .^{\circ}$, quer do $2 .^{\circ}$ ciclo. Nesse tipo de tarefas, também os próprios futuros professores sentem muitas dificuldades, conforme se mostra em variados estudos de que participaram estudantes com uma formação semelhante à dos que integraram o presente estudo (Fernandes et al., 2014; Fernandes, Gea e Batanero, 2016; Fernandes, Viseu e Gea, 2016). Essas dificuldades ocorreram por conta de erros em relacionar probabilidades de experiências simples com probabilidades de experiências compostas, em não levar em conta a reposição/ não reposição da experiência aleatória e em não atender à ordem na identificação dos resultados da experiência composta (Fernandes, Gea e Batanero, 2016). Na Figura 2, apresenta-se uma situação de determinação de probabilidades em experiências compostas.

\section{Um saco preto tem: 2 rebuçados de laranja, 2 de morango e 2 de limão. \\ Qual é a probabilidade de retirar, sem ver, dois do mesmo sabor? \\ Qual é a probabilidade de retirar, sem ver, um de cada sabor?}

Figura 2 - Tarefa apresentada pelo estudante $E_{26}$ para o $10^{\circ}$ ciclo.

Além de tratar-se de uma tarefa complexa, pois requer compreender a experiência composta de extrair dois rebuçados, o enunciado é incompleto, já que não se indica o modo como se realiza a extração dos dois rebuçados. Como consequência dessa imprecisão, a resposta ao primeiro item é $\frac{1}{5}$ se não se considera a reposição, e $\frac{1}{3}$ se há reposição.

Esse tipo de tarefas envolvendo a determinação de probabilidades em experiências compostas está fora do alcance da generalidade dos alunos do $1 .^{\circ} \mathrm{e}$ do $2 .^{\circ}$ ciclo, por não serem adequadas para esses alunos. Mais complicado ainda é o fato de algumas dessas tarefas ( $50 \%$ no $1 .^{\circ}$ ciclo e $25 \%$ no $2 .^{\circ}$ ciclo) envolverem a repetição da experiência aleatória simples três ou mais vezes. Ora, essas situações implicam o uso de técnicas de contagem mais sofisticadas, que naturalmente os alunos do $1^{\circ}$ e do $2^{\circ}$ ciclo não dominam.

Já as experiências aleatórias simples são mais adequadas ao nível escolar dos alunos que esses futuros professores terão de ensinar. Todavia, tendo por referência o programa escolar (Portugal, 2007), verifica-se que a determinação de um valor numérico do intervalo $[0,1]$, enquanto medida da incerteza, não é estudada no nível 
escolar em questão, mas apenas no $9 .^{\circ}$ ano, que é o último do $3 .^{\circ}$ ciclo do ensino básico. Na próxima seção, em que se descrevem os diferentes tipos de probabilidade requeridos nas tarefas, pode-se atestar a elevada percentagem de futuros professores que apresentaram tarefas desse tipo.

Finalmente, no caso da experiência aleatória indefinida, não é clara a tarefa proposta, não se percebe o que se pretende ou como obter a resposta, como acontece com a seguinte tarefa, da Figura 3.

\section{Um carro gasta $10 \mathrm{~L}$ aos 100 . O Rui atestou o carro, metendo $60 €(1 \mathrm{~L}=1,47 €)$. \\ Sabendo que anda entre os 80 e os $120 \mathrm{~km} / \mathrm{h}$, entre que dias se prevê que o carro atinja a reserva? Qual é a probabilidade de ser dias de número par? E ímpar?}

Figura 3 - Tarefa apresentada pelo estudante $E_{20}$ para o $2 .^{\circ}$ ciclo.

Nessa tarefa da Figura 3 não se nota a natureza aleatória do fenômeno em estudo nem como obter a resposta às questões formuladas, pois supomos que, quando o estudante $E_{20}$ menciona a velocidade (entre 80 e 120 km/h), quer referir-se à distância que pensa percorrer (entre 80 e $120 \mathrm{~km}$ ) uma vez colocada gasolina no carro, pelo que, ao consumir $1 \mathrm{~L}$ aos $10 \mathrm{~km}$, não chegará nunca à reserva nessas distâncias. Também não se entende a motivação para calcular a probabilidade em dia par ou ímpar se não se dá informação de como esse dado influi no contexto do problema.

Considerando agora o conjunto das três tarefas propostas por cada estudante, verifica-se que todas as tarefas de $58 \%$ dos estudantes envolvem apenas experiências simples, $2 \%$ somente experiências compostas, $36 \%$ abrangem experiências simples e compostas e em $4 \%$ não é possível atribuir o tipo de experiência aleatória. Assim, nessa análise, destaca-se que elevada percentagem de futuros professores (38\%) propôs pelo menos uma tarefa em experiências compostas dirigida a alunos do $1^{\circ}$ ou do $2^{\circ}$ ciclo.

\section{Tipo de atividade requerida}

Nesta dimensão, estudam-se os itens constantes das tarefas formuladas pelos estudantes para determinar o tipo de atividade que se pede para resolver. Tendo em conta que alguns estudantes apresentaram mais do que um item em algumas tarefas, na Tabela 2, apresentam-se as frequências desses itens tendo em consideração o tipo de atividade requerida, designadamente o cálculo de probabilidades (simples, conjunta, condicionada, da reunião e envolvendo a negação), a comparação de probabilidades de acontecimentos, assim como a classificação e formulação de acontecimentos, segundo o ciclo de ensino.

Observa-se pela Tabela 2 que a determinação de uma probabilidade simples, envolvendo um único acontecimento (simples ou composto), foi o tipo de item mais formulado pelos estudantes, tanto no $1 .^{\circ}$ como no $2 .^{\circ}$ ciclo. Na Figura 4 está a tarefa proposta por um desses estudantes.

A resolução dos três itens da tarefa proposta pelo estudante $E_{5}$ requer a determinação do valor numérico de uma probabilidade, o que está para além do programa escolar do $2 .^{\circ}$ ciclo do ensino básico, conforme já antes foi dito, pelo que não é muito adequado dirigi-la para o $1 .^{\circ}$ ciclo, tal como indicou o estudante. 
Tabela 2 - Frequência (\%) de itens segundo o tipo de atividade e o ciclo de ensino.

\begin{tabular}{l|c|c|c}
\hline \multirow{2}{*}{ Tipo de atividade } & \multicolumn{2}{|c|}{ Ciclo de ensino } & \multirow{2}{*}{ Total } \\
\cline { 2 - 3 } & $1^{0}{ }^{0}$ ciclo & $2^{0}{ }^{0}$ ciclo & \\
\hline Probabilidade simples & $82(67)$ & $54(43)$ & $136(55)$ \\
\hline Probabilidade conjunta & $17(14)$ & $36(28)$ & $53(21)$ \\
\hline Comparar probabilidades & $10(8)$ & $8(6)$ & $18(7)$ \\
\hline Probabilidade condicionada & $7(6)$ & $9(7)$ & $16(6)$ \\
\hline Probabilidade da reunião & $4(3)$ & $4(3)$ & $8(3)$ \\
\hline Probabilidade envolvendo a negação & $3(2)$ & $1(1)$ & $4(2)$ \\
\hline Classificar/formular acontecimentos & - & $15(12)$ & $15(6)$ \\
\hline
\end{tabular}

Temos um saco com 3 bolas verdes, 4 bolas brancas e 2 bolas pretas.

Tira-se uma bola ao acaso do saco.

a) Qual é a probabilidade de sair bola branca?

b) Qual é a probabilidade de sair bola verde?

c) Qual é a probabilidade de sair bola preta?

Figura 4-Tarefa apresentada pelo estudante $E_{5}$ para o $1 .^{\circ}$ ciclo.

De seguida, com maior incidência no $2 .^{\circ}$ ciclo, encontram-se os itens em que se pede para calcular a probabilidade conjunta, relativa à probabilidade da interseção de dois acontecimentos, que se exemplifica na Figura 5.

Numa turma de 50 alunos, sabe-se que 15 jogam futebol e 30 praticam natação.

Escolhendo-se ao acaso 1 aluno, qual é a probabilidade de ele praticar ambos os desportos?

Figura 5 - Tarefa apresentada pelo estudante $E_{27}$ para $02 .^{\circ}$ ciclo.

Os dados fornecidos na tarefa proposta pelo estudante $E_{27}$ são insuficientes para a resolver, pois não é possível determinar o número total de alunos que jogam futebol e praticam natação simultaneamente.

No caso da comparação de probabilidades, são muito menos os itens formulados pelos alunos, observando-se incidência semelhante nos dois ciclos de ensino. A comparação entre as probabilidades de dois ou mais acontecimentos constitui um tipo de tarefa que poderá ser resolvida sem recurso à quantificação numérica da probabilidade, podendo assumir-se como uma introdução a esse conceito (Fischbein e Schnarch, 1997). Os poucos itens formulados pelos estudantes nesse tipo de atividade podem ser vistos como a desvalorização dessa perspectiva no ensino, apesar de esse tipo de tarefa ser compatível com o que é preconizado no programa escolar de Matemática desses níveis escolares. A Figura 6 exibe uma tarefa que pode ser resolvida sem recorrer-se à definição de probabilidade. 


\section{Num saco existem 2 bolas brancas e 2 bolas pretas. \\ É mais provável sair uma bola branca, uma bola preta ou a probabilidade é igual?}

Figura 6 - Tarefa apresentada pelo estudante $E_{8}$ para o $1 .^{\circ}$ ciclo.

Para responder à tarefa, basta observar, adotando um raciocínio aditivo, que no saco há tantas bolas brancas como pretas, donde será igualmente provável tirar uma bola de cada uma das duas cores.

A probabilidade condicionada, a probabilidade da reunião de acontecimentos e a de acontecimentos envolvendo a negação são referidas em poucos itens, e a sua incidência não se destaca em nenhum dos dois ciclos de ensino. No caso da negação, os poucos itens formulados pelos futuros professores envolvem no seu enunciado a operação de negação, não implicando necessariamente a determinação da probabilidade por meio da relação entre as probabilidades do acontecimento e do seu contrário. A seguir, na Figura 7, apresenta-se uma tarefa com dois itens, o primeiro envolvendo a negação e o outro a probabilidade condicionada.

Num baralho com 40 cartas:
Qual é a probabilidade de não retirar um ás de espadas?
Qual é a probabilidade de retirar rei sabendo que tira dama?

Figura 7 -Tarefa apresentada pelo estudante $E_{37}$ para o $1 .^{\circ}$ ciclo.

No caso da negação, a probabilidade pode ser determinada considerando, como casos favoráveis, todas as cartas diferentes do ás de espadas (39 cartas); no caso da probabilidade condicionada, ela pode ser determinada pela restrição do espaço amostral.

Finalmente, apenas no $2 .^{\circ}$ ciclo, poucos são os itens que versam sobre a classificação e formulação de acontecimentos. Entre esses itens, quase todos se referem à classificação de acontecimentos em certos, possíveis (mas não certos) e impossíveis (80\%), enquanto a formulação desses tipos de acontecimentos é mencionada em menos itens (20\%). Verifica-se, assim, que os futuros professores, em geral, não tiveram em consideração esse tipo de tarefa, embora seja um tipo de tarefa que faz parte dos programas de Matemática desses níveis escolares (Portugal, 2007). Na Figura 8, apresenta-se uma tarefa de classificação de acontecimentos.

\section{Lança-se um dado e conta-se o número de pintas da face voltada para cima.}

É certo, possível ou impossível obter:

$$
\text { a) O número } 5
$$

b) Um número par

c) Um número menor que 9

d) Um número maior que um

e) Um número inteiro

Figura 8 - Tarefa apresentada pelo estudante $E_{22}$ para o 2. ${ }^{\circ}$ ciclo. 
Nessa tarefa, trata-se de classificar vários acontecimentos em certo, possível ou impossível, que é um tipo de classificação alternativa à dos acontecimentos em improvável, provável e muito provável.

Os resultados obtidos na análise informam-nos do limitado conhecimento didático dos futuros professores nas facetas epistêmica, cognitiva e ecológica, pois propõem um elevado número de itens (30\%) cuja solução requer o domínio de conteúdos probabilísticos específicos (linguagens, definições, procedimentos etc.) que não se encontram disponíveis no ciclo de ensino a que se dirigem; e propõem pouquíssimas tarefas (13\%) sobre a comparação de probabilidades e classificação e formulação de acontecimentos, omitindo também tarefas sobre a exploração da noção de experiência aleatória e a linguagem e terminologia do acaso.

Alsina e Vásquez (2016), utilizando o marco de investigação que aplicamos na nossa investigação, mostram o escasso CDM para ensinar probabilidades de uma amostra de 93 professores chilenos em exercício, em que a única variável que incide nas pontuações dos professores é a sua formação acadêmica (especialidade em Matemática) e não a sua experiência, o tipo de escola ou o gênero. Conclusões similares estabelecem Contreras et al. (2010) quando analisam as respostas de uma amostra de 69 futuros professores a questões elementares sobre cálculo de probabilidades (simples, conjunta e condicionada) numa tabela de contingência, quando comparam os seus resultados com os da investigação de Estrada e Díaz (2006) numa tarefa similar numa amostra de 65 futuros professores com maior preparação em estatística que os anteriores, pois frequentavam uma disciplina de Matemática e sua didática, em que um dos seus quatro temas era estatística e probabilidades, e uma opcional de estatística, o que justifica a maior formação estatística desses estudantes.

Tipo de contexto

Os contextos em que as tarefas foram formuladas são variados. Na Tabela 3 estão registrados as frequências de tarefas relativas a cada um dos contextos em que se inserem e o ciclo de ensino, e conclui-se que a maioria das tarefas diz respeito ao contexto de jogos de sorte e azar, que se destaca claramente de todos os demais.

Tabela 3 - Frequência (\%) de tarefas segundo o tipo de contexto e o ciclo de ensino.

\begin{tabular}{l|c|c|c}
\hline Contexto & 1. ${ }^{0}$ ciclo & 2. ${ }^{0}$ ciclo & Total \\
\hline Jogos de sorte e azar & $50(61)$ & $42(55)$ & $92(58)$ \\
\hline Turma/Escola & $21(26)$ & $24(31)$ & $45(28)$ \\
\hline Pessoas & $2(2)$ & $7(9)$ & $9(6)$ \\
\hline Outro & $9(11)$ & $4(5)$ & $13(8)$ \\
\hline
\end{tabular}

Mais especificamente, esse contexto refere-se a urnas, baralhos de cartas, dados, moedas e roletas, entre os quais se salienta o contexto de urna (68\% no $1 .^{\circ}$ ciclo e $55 \%$ no $2 .^{\circ}$ ciclo), e dos restantes não se destaca nenhum deles. Ainda no caso do contexto de urna, observa-se que a maioria das tarefas se refere à extração 
de bolas e berlindes, estando envolvida nas restantes tarefas a extração de rebuçados, cartões, figuras etc. A tarefa da Figura 9 insere-se no contexto de jogos de sorte e azar, envolvendo uma roleta.

Observar a seguinte roleta.

Qual é o número que é mais provável de sair? E menos provável?

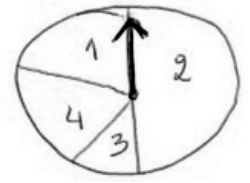

Figura 9 - Tarefa apresentada pelo estudante $E_{53}$ para o $10^{\circ}$ ciclo.

A resolução dos dois itens dessa tarefa, que pode consistir numa estratégia de comparação, implica uma avaliação aproximada das áreas dos diferentes setores da roleta.

Em ambos os ciclos, uma percentagem considerável de tarefas diz respeito ao contexto da turma ou da escola, prevalecendo o contexto da turma ( $85 \%$ no 1 . $^{\circ}$ ciclo e $56 \%$ no $2 .^{\circ}$ ciclo). No conjunto dessas tarefas, verifica-se que metade ou mais ( $50 \%$ no $1 .^{\circ}$ ciclo e $56 \%$ no $2 .^{\circ}$ ciclo) envolve dois atributos, correspondentes a dois acontecimentos, como, por exemplo: gênero e curso; gênero e futebol; futebol e natação. Para esse tipo de tarefas, podendo abranger uma atividade sobre probabilidade simples, conjunta, condicionada, da reunião e da negação, é especialmente adequada a representação em diagrama de Venn, que os alunos manusearam nos primeiros anos do $10^{\circ}$ ciclo ao realizar operações lógicas de classificação. Destaca-se ainda, no conjunto dessas últimas tarefas, a prevalência do atributo gênero, que é referido na maioria das situações, seja de forma isolada, seja combinado com outro atributo ( $55 \%$ no $1 .^{\circ}$ ciclo e $36 \%$ no $2 .^{\circ}$ ciclo). Na Figura 10 , apresenta-se um exemplo de tarefa desse último tipo.

\footnotetext{
Numa turma de 60 alunos, sabe-se que metade é rapariga e metade é rapaz.
Sabe-se também que metade das raparigas toca violino e $2 / 3$ da turma toca guitarra.
Escolhendo ao acaso, qual é a probabilidade de ser rapaz e tocar guitarra?

Figura 10 - Tarefa apresentada pelo estudante $E_{48}$ para $02 .^{\circ}$ ciclo.

Essa tarefa envolve os atributos rapariga/rapaz e tocar violino/guitarra, o que the confere elevado grau de dificuldade para os alunos a quem se dirige. Por outro lado, os dados fornecidos são insuficientes para responder à questão formulada.

Por último, foram poucas as tarefas relativas aos contextos pessoais e outro, não se salientando qualquer tipo de contexto mais específico em nenhuma dessas tarefas.

Analisando agora o número de contextos distintos nas três tarefas propostas pelos estudantes, verifica-se que apenas $10 \%$ deles adotam três contextos distintos, $60 \%$ adotam dois contextos distintos e $30 \%$ apenas um contexto. Ainda que a maio- 
ria dos estudantes (70\%) defina as suas tarefas em dois ou mais contextos distintos, uma elevada percentagem só recorre a um contexto na formulação das tarefas, o que contradiz os princípios metodológicos indicados nas diretrizes curriculares para o ensino básico (Portugal, 2013).

\section{Referência à incerteza}

Nesta dimensão, analisa-se a referência à incerteza nos enunciados das tarefas propostas pelos alunos. Por exemplo, quando a tarefa diz respeito à extração de uma bola de um saco ou de uma carta de um baralho, é importante explicar que essa extração é feita "sem ver", "com os olhos fechados" ou "ao acaso", pois a imprevisibilidade do resultado da experiência está dependente de uma tal ação de extração. Já no caso do lançamento de uma moeda e de um dado ou de rodar uma roleta, tal procedimento não se reveste da mesma relevância, e a simples menção a "lançar" ou "rodar" o objeto em questão levou a considerar a tarefa como aludindo indiretamente à incerteza. $\mathrm{Na}$ Tabela 4 , apresentam-se as frequências de tarefas segundo a referência à incerteza e o ciclo de ensino.

Tabela 4 - Frequência (\%) de tarefas segundo a referência à incerteza e o ciclo de ensino.

\begin{tabular}{l|c|c|c}
\hline Incerteza & 1. $^{\circ}$ ciclo & 2. ${ }^{\circ}$ ciclo & Total \\
\hline Com alusão à incerteza & $38(46)$ & $30(39)$ & $68(43)$ \\
\hline Sem alusão à incerteza & $36(44)$ & $39(51)$ & $75(47)$ \\
\hline Fenômeno determinista & $8(10)$ & $8(10)$ & $16(10)$ \\
\hline
\end{tabular}

$\mathrm{Na}$ alusão à incerteza, os alunos usaram, fundamentalmente, as expressões "sem ver", "com os olhos fechados" e "ao acaso", tendo-se verificada incidência dessa referência um pouco superior nas tarefas do $1 .^{\circ}$ ciclo. A tarefa da Figura 11 , no contexto da escola, ilustra a alusão à incerteza ao pedir o cálculo de uma probabilidade simples.

Dos alunos de uma escola, sabe-se que 80 são rapazes e 100 são raparigas.

Escolhendo um aluno ao acaso para representar a escola, qual é a probabilidade de ser rapariga?

Figura 11 - Tarefa apresentada pelo estudante $E_{14}$ para o $1 .^{\circ}$ ciclo.

Na tarefa, o estudante inclui no enunciado a expressão "ao acaso", a qual permite evidenciar a natureza incerta do resultado da experiência aleatória em questão.

Já em relação às tarefas em que não se faz referência à incerteza, a situação é inversa, observando no $2 .^{\circ}$ ciclo a maior frequência dessas tarefas. Considerando 
globalmente as tarefas com e sem alusão à incerteza, conclui-se que aquelas que não aludem à incerteza são em número um pouco superior, quase metade da totalidade das tarefas, sendo maior essa diferença no $2 .^{\circ}$ ciclo, em que mais de metade das tarefas não se refere à incerteza.

Finalmente, algumas tarefas dizem respeito a fenômenos deterministas, que não envolvem nenhum grau de incerteza. A questão da incerteza é inerente aos fenômenos aleatórios, os quais, por sua vez, são objeto de estudo em probabilidades. Assim, a questão da alusão à incerteza nos enunciados das tarefas de probabilidades é um aspecto importante que deve ser criteriosamente incluído nos respectivos enunciados. Na Figura 12, pode-se ver um exemplo desse tipo de tarefas.

O Tiago dividiu um tabuleiro de bolo em 16 partes.

Ele comeu 3/8 do bolo e a Joana comeu 2/4.

Quantas fatias de bolo comeram no total?

Figura 12 - Tarefa apresentada pelo estudante $E_{10}$ para o $1 .^{\circ} \mathrm{e} 2 .^{\circ}$ ciclo.

Essa tarefa não envolve nenhuma incerteza e, apesar do pouco rigor na escrita do enunciado, no uso dos termos "partes" e "fatias", sem dizer que são iguais, basta recorrer às operações elementares para obter a resposta pretendida.

Comparativamente com não aludir à incerteza no enunciado da tarefa, consideramos mais grave formular tarefas deterministas em vez de tarefas probabilísticas, que eram as solicitadas. Nesse último caso, o estudante revela contradizer a incerteza como propriedade fundamental característica dos fenômenos aleatórios (Bryant e Nunes, 2012).

Considerando agora o conjunto das três tarefas propostas pelos estudantes, verifica-se que, direta ou indiretamente, apenas $15 \%$ dos estudantes aludem à incerteza em todas as três tarefas, $60 \%$ indicam a incerteza em uma ou duas tarefas e $25 \%$ não mencionam a incerteza em nenhuma das tarefas que propõem. Desses resultados, destaca-se que a maioria dos estudantes não aludiu sistematicamente à incerteza, fazendo-o umas vezes e outras não, o que pensamos ser um resultado do presente estudo muito importante, com implicações para a formação desses futuros professores.

\section{CONCLUSÃO}

$\mathrm{Na}$ formulação das tarefas para ensinar probabilidades aos alunos dos primeiros anos, os futuros professores precisam mobilizar variadas componentes do conhecimento (Godino et al.,2017). Neste trabalho, baseamo-nos nas componentes epistêmica, cognitiva e ecológica do CDM do professor, descrito no marco teórico do enfoque ontossemiótico.

Verificou-se que, em geral, na componente epistêmica, o conhecimento dos futuros professores para ensinar probabilidades aos alunos dos primeiros anos é 
muito limitado e desadequado diante das capacidades cognitivas desses alunos e das diretrizes curriculares desse nível de ensino. Tal desadequação em termos cognitivos é evidenciada no tipo de experiência aleatória, na não referência à incerteza nem no tipo de atividade requerida, em que a determinação de probabilidades em experiências compostas (probabilidades conjuntas, condicionadas, da reunião e envolvendo a negação) estão para além das capacidades cognitivas dos alunos do $1 .^{\circ}$ e do $2 .^{\circ}$ ciclo do ensino básico. Adicionalmente, é de realçar que os próprios futuros professores revelam muitas dificuldades na determinação dessas probabilidades (Contreras et al., 2010; Fernandes et al., 2014; Fernandes, Viseu e Gea, 2016). Alsina e Vásquez (2016) também notaram que professores chilenos do ensino primário revelaram conhecimento do conteúdo muito limitado, recomendando que eles aprofundem o seu CDM.

No caso de alunos dos $8 .^{\circ}$ e $11 .^{\circ}$ anos, Fernandes (2001) constatou que esses estudantes depararam com muitas dificuldades na resolução de cinco itens envolvendo experiências compostas. Essas dificuldades foram mais acentuadas nos alunos do $8 .^{\circ}$ ano, que são de um ano de escolaridade mais avançado do que aqueles a quem se dirigiam as tarefas dos futuros professores, tendo-se visto percentagem de respostas corretas variando entre 12,8 e $37,7 \%$.

Apesar de a maioria dos futuros professores envolver experiências simples em todas as tarefas, em termos da componente ecológica do conhecimento do futuro professor, verifica-se desadequação acentuada, pois o programa escolar (Portugal, 2007) foca sobretudo na exploração da noção de experiência aleatória, na linguagem e terminologia do acaso e na classificação e formulação de acontecimentos, não fazendo referência à determinação de probabilidades enquanto valor de quantificação da incerteza.

$\mathrm{Na}$ variável contexto, ainda que a maioria dos futuros professores estabeleça as três tarefas em dois ou mais contextos distintos, $30 \%$ deles só recorrem a um contexto para as três tarefas, o que revela o limitado conhecimento curricular que possuem em relação aos princípios metodológicos para o ensino básico indicados no currículo (Portugal, 2013, p. 1), que afirma:

O desenvolvimento da compreensão - que resulta da ampliação contínua e gradual de uma complexa rede de regras, procedimentos, factos, conceitos e relações que podem ser mobilizados, de forma flexível, em diversos contextos - deve ocupar o centro das preocupações das escolas e dos professores. (Portugal, 2013, p. 1)

A maior referência aos jogos de sorte e azar constitui uma orientação adequada tendo em conta as orientações curriculares (Portugal, 2007, 2013; National Council of Teachers of Mathematics, 2007) e o fato de se tratar de situações simples e claras do acaso. A esse respeito, é esclarecedor que esses atributos dos jogos de sorte e azar expliquem o fato de eles terem estado na origem das probabilidades enquanto domínio científico, que aconteceu por volta do século XVII com os trabalhos de Pascal e Fermat. Adicionalmente, para Borovcnik e Pearl (1996), a vantagem em traduzir certo problema para um 
contexto de urnas ou roletas pode ser vista enquanto referência a probabilidades numéricas, capazes de ser facilmente lidas desses objetos, e para promover o pensamento conceitual.

Apesar de a maioria dos futuros professores referir-se à incerteza em uma ou duas tarefas, a não referência à incerteza ou a consideração de situações deterministas, em mais de metade de todas as tarefas, constituem um aspecto problemático, pois revela que os futuros professores não discriminam os fenômenos aleatórios dos fenômenos deterministas, o que é condição fundamental da componente epistêmica do conhecimento do futuro professor no ensino do tema. Para Bryant e Nunes (2012), a aquisição do conceito de probabilidade requer quatro exigências cognitivas: aleatoriedade, espaço amostral, avaliação das probabilidades e associação estatística. Ora, a aleatoriedade, para além de envolver a distinção entre sequências aleatórias e não aleatórias, a independência e a seleção e atribuição aleatória, envolve também a incerteza, que é um aspecto particularmente relevante nos primeiros anos escolares.

No momento do desenvolvimento da pesquisa, os futuros professores tinham estudado probabilidades, sobretudo numa vertente epistêmica. Para além de apresentarem dificuldades nessa vertente, eles mostraram limitações do seu conhecimento na componente epistêmica quando propuseram as tarefas, como foi patente nos enunciados pouco rigorosos e precisos e na falta de dados que permitam resolvê-las (ver Figuras 2, 3, 5 e 10). O conhecimento adquirido pelos futuros professores nesse âmbito não se revelou suficiente para eles ensinarem probabilidades aos alunos dos primeiros anos.

Por tudo isso, ao nível das vertentes cognitiva, epistêmica e ecológica, as tarefas propostas pelos futuros professores revelaram-se pouco adequadas para os alunos dos primeiros anos, sendo essas tarefas muito influenciadas pelas aprendizagens por eles adquiridas no tema de probabilidades de uma unidade curricular que tinham frequentado imediatamente antes no seu curso universitário.

Embora a identificação das suas próprias aprendizagens com as dos alunos dos primeiros anos possa vir a ser atenuada com a prática letiva, sobretudo com a ajuda dos manuais escolares, esse resultado não deixa de ser muito preocupante ao nível das possibilidades de aprendizagem dos alunos e do não reconhecimento de que o conhecimento no horizonte matemático é um conhecimento matemático que vai além dos conhecimentos atuais de ensino (Hill, Ball e Schilling, 2008).

Assim, no presente estudo, concluiu-se claramente que o conhecimento de probabilidades não é suficiente para ensinar esse tema aos alunos dos primeiros anos, sendo necessário que os futuros professores desenvolvam durante a sua formação inicial competências de didática sobre probabilidades que lhes permitam planificar, implementar e avaliar adequadamente as aprendizagens dos alunos (Godino et al., 2017). Para tal, é necessário que os formadores desses futuros professores incorporem nos planos de estudo, além de componentes do conhecimento de probabilidades, também componentes do conhecimento didático de probabilidades. 


\section{REFERÊNCIAS}

ALSINA, A.; VÁSQUEZ, C. Análisis de los conocimientos probabilísticos del profesorado de Educación Primaria. Revista Digital Matemática, Educación e Internet, Costa Rica, v. 16, n. 1, 2016. https://doi.org/10.18845/rdmei.v16i1.2475

ALVES, M.P.; FERNANDES,J. A. Alterações do programa de matemática do ensino básico português: o caso do tema Organização e Tratamento de Dados. Olh@res, Guarulhos, v. 3, n. 1, p. 280-305, 2015.

BATANERO, C. Retos para la formación estadística de los profesores. In: FERNANDES, J. A. et al. (orgs.). ENCONTRO DE PROBABILIDADES E ESTATÍSTICA NA ESCOLA, 2., 2009. Atas [...]. Braga: Centro de Investigação em Educação da Universidade do Minho, 2009. p. 52-71.

BATANERO, C. La comprensión de la probabilidad en los niños: ¿qué podemos aprender de la investigación? In: FERNANDES, J. A. et al. (orgs.). ENCONTRO DE PROBABILIDADES E ESTATÍSTICA NA ESCOLA, 3., 2013. Atas [...]. Braga: Centro de Investigação em Educação da Universidade do Minho, 2013. p. 9-21.

BATANERO, C.; CHERNOFF, E. Teaching and Learning Stochastics: Advances in Probability Education Research, ICME-13 Monographs. Suíça: Springer, 2018.

BATANERO, C. et al. Research on teaching and learning probability, ICME-13 Topical Surveys. Nova York: Springer, 2016.

BOROVCNIK, M.; PEARD, R. Probability. In: BISHOP, A. J. et al. (orgs.). International handbook of mathematics education. Dordrecht: Kluwer Academic Publishers, 1996. p. 239-287.

BRYANT, P.; NUNES, T. Children's understanding of probability: A literature review (full report). Londres: The Nuffield Foundation, 2012.

CONTRERAS, J. M. et al. Dificultades de futuros profesores en la lectura y cálculo de probabilidades en tablas de doble entrada. In: MORENO, M. M. et al. (orgs.). Investigación en educación matemática XIV. Lleida: Sociedad Española de Investigación en Educación Matemática, SEIEM, 2010. p. 271-280.

ESTRADA, A.; DÍAZ, C. Computing probabilities from two way tables. An exploratory study with future teachers. In: ROSSMAN, A.; CHANCE, B. (orgs.). INTERNATIONAL CONFERENCE ON TEACHING OF STATISTICS, 7., 2006. Proceedings [...]. Salvador: International Association for Statistical Education, 2006. CD-ROM.

FERNANDES, J. A. Intuições probabilísticas em alunos do $8 .^{\circ}$ e $11 .^{\circ}$ anos de escolaridade. Quadrante, Lisboa, v. 10, n. 2, p. 3-32, 2001.

FERNANDES, J. A. et al. Desempenho em probabilidade condicionada e probabilidade conjunta de futuros professores do ensino básico. Quadrante,Lisboa,v.23, n.1,p.43-61,2014. FERNANDES, J. A.; GEA, M. M.; BATANERO, C. Conocimiento de futuros profesores de Educación Primaria sobre probabilidad en experiencias compuestas. In: MACÍAS, J. A. et al. (orgs.). Investigación en Educación Matemática XX. Málaga: SEIEM, 2016. p. 217-225. 
FERNANDES, J. A.; VISEU, F.; GEA, M. M. O conhecimento de Probabilidades de futuros educadores e professores dos primeiros anos. In: COAN, L. G. W.; MORETTI, M. T. (orgs.). Aplicações matemáticas com Tecnologias de Informação e Comunicação. Florianópolis: Insular, 2016. p. 123-142.

FISCHBEIN, E.; SCHNARCH, D. The evolution with age of probabilistic, intuitively based misconceptions. Journal for Research in Mathematics Education, Reston, v. 28, n. 1, p. 96-105, 1997. https://psycnet.apa.org/doi/10.2307/749665

GODINO, J. D. Categorías de análisis de los conocimientos del profesor de matemáticas. Unión Revista Iberoamericana de Educación Matemática, La Laguna, n. 20, p. 13-31, 2009.

GODINO,J.D.; BATANERO, C.; FONT, V. The onto-semiotic approach to research in mathematics education. ZDM. The International Journal on Mathematics Education, Berlim, v. 39, n. 1-2, p. 127-135, 2007. http://doi.org/10.1007/s11858006-0004-1

GODINO, J. D. et al. Enfoque ontosemiótico de los conocimientos y competencias del profesor de matemáticas. Bolema, Rio Claro, v. 31, n. 57, p. 90-113, 2017. http:// dx.doi.org/10.1590/1980-4415v31n57a05

HILL, H. C.; BALL, D. L.; SCHILLING, S. G. Unpacking pedagogical content knowledge: Conceptualizing and measuring teachers' topic-specific knowledge of students. Journal for Research in Mathematics Education, Reston, v. 39, n. 4, p. 372-400, 2008.

HILL, H. C. et al. Assessing teachers' mathematical knowledge. What Knowledge Matters and What Evidence Counts? In: LESTER, F. K. (org.). Second Handbook of Research on Mathematics Teaching and Learning. A Project of the National Council of Teachers of Mathematics. Greenwich: Information Age Publishing, Inc. \& NCTM, 2007. p. 111-155.

LLINARES, S.; KRAINER, K. Mathematics (Student) Teachers and Teacher Educators as Learners. In: GUTIERREZ, A.; BOERO, P. (orgs.). Handbook of Research on the Psychology of Mathematics Education. Past, Present and Future. Rotherdam / Taipei: Sense Publishers, 2006. p. 429-459.

NATIONAL COUNCIL OF TEACHERS OF MATHEMATICS. Princípios e normas para a matemática escolar. Lisboa: Associação de Professores de Matemática, 2007. PINO-FAN, L.; GODINO, J. D. Perspectiva ampliada del conocimiento didácticomatemático del profesor. Paradigma, Venezuela, v. 36, n. 1, p. 87-109, 2015.

POLAKI, M. V. Dealing with compound events. In: JONES, G. A. (org.). Exploring probability in school: challenges for teaching and learning. Nova York: Springer, 2005. p. 191-214.

PONTE, J. P. Estudiando el conocimiento y el desarrollo profesional del profesorado de matemáticas. In: PLANAS, N. (coord.). Teoría, crítica y práctica de la educación matemática. Barcelona: Graó, 2012. p. 83-98.

PORTUGAL. Ministério da Educação. Programa de Matemática do ensino básico. Lisboa: Ministério da Educação, 2007. 
PORTUGAL. Ministério da Educação e Ciência. Programa de matemática para o ensino básico. Lisboa: Ministério da Educação, 2013.

SHULMAN, L. S. Those who understand: Knowledge growth in teaching. Educational Researcher, Londres, v. 15, n. 2, p. 4-14, 1986. https://doi. org/10.3102\%2F0013189X015002004

WATSON, J. The probabilistic reasoning of middle school students. In: JONES, G. A. (org.). Exploring probability in school: challenges for teaching and learning. Nova York: Springer, 2005. p. 145-169.

WEBER, R. P. Basic content analysis. Londres: Sage, 1985.

\section{SOBRE OS AUTORES}

José António Fernandes é doutor em educação pela Universidade do Minho (Portugal). Professor da mesma instituição.

E-mail: jfernandes@ie.uminho.pt

María Magdalena Gea Serrano é doutora em ciências da educação pela Universidade de Granada (Espanha). Professora da mesma instituição. E-mail:mmgea@ugr.es

Leandro do Nascimento Diniz é doutor em ciências da educação pela Universidade do Minho (Portugal). Professor da Universidade Federal do Recôncavo da Bahia (UFRB).

E-mail: leandro@ufrb.edu.br

Recebido em 9 de maio de 2018

Aprovado em 2 de maio de 2019 